\title{
Linear, branched and network polysilanes with thienyl/furyl substituted sila-alkyl side chains and their applications for the synthesis of fluorescent silver nanoparticles/clusters
}

\author{
RAVI SHANKAR*, USHARANI SAHOO, VANDANA SHAHI and MANCHAL CHAUDHARY \\ Department of Chemistry, Indian Institute of Technology, New Delhi 110016, India \\ e-mail: shankar@chemistry.iitd.ac.in
}

\begin{abstract}
The scope of Wurtz coupling and catalytic dehydrocoupling methods for the synthesis of functional polysilanes of compositions, [RR'Si $]_{\mathrm{n}}$ (linear), $\left[(\mathrm{PhMeSi})_{\mathrm{x}}-\mathrm{co}-(\mathrm{RSi})_{1-\mathrm{x}}\right]_{\mathrm{n}}$ (branched) and $[\mathrm{RSi}]_{\mathrm{n}}($ network) $\left[\mathrm{R}=\mathrm{Et}_{3} \mathrm{SiCH}_{2} \mathrm{CH}_{2}, 2-\mathrm{Fu} / 2-\mathrm{ThMe}_{2} \mathrm{SiCH}_{2} \mathrm{CH}_{2}\left(\mathrm{Fu}=\mathrm{Furyl}\right.\right.$, $\mathrm{Th}=$ Thienyl), $n$-Hex or $\mathrm{Ph} ; \mathrm{R}^{\prime}=\mathrm{H}$ or Me $]$ is presented. By virtue of $\sigma$-delocalized silicon backbone and variable HOMO-LUMO band gap energies, these polymers are found to be promising candidates as reducing agents for $\mathrm{Ag}(\mathrm{I})$ ions in toluene/cyclo-hexane and provide a simple approach for 'size-controlled' synthesis of silver nanoparticles (AgNPs) as well as fluorescent polymer-silver nanocomposites.
\end{abstract}

Keywords. Polysilanes; silver nanoparticles/clusters; fluorescent, nanocomposites.

\section{Introduction}

Extensive studies on synthesis and electronic attributes of high molecular weight polysilanes in the past have provided a great deal of thrust to explore potential applications of these polymers in the field of optoelectronics, semiconducting materials as well as ceramics. ${ }^{1-3}$ Depending on the dimensionality of silicon frameworks, these polymers are classified as linear, branched and network polysilanes (chart 1). An alternate nomenclature for these polymers as poly(silylene), poly(silylene-cosilyne) and poly(silyne), respectively is also subscribed in literature.

It is now well-established that electronic properties associated with $\sigma$-electron delocalized silicon backbone are quite distinct for each class of polysilanes and can be tuned by varying the side chain substituents and/or dimensionality of skeletal framework. Earlier work on branched polysilanes ${ }^{4,5}$ have shown that linear and branched units of these polymers more or less behave as separate chromophores and exhibit distinct photophysical properties with characteristic emission bands being observed at $\sim 350-360$ and $\sim 450 \mathrm{~nm}$, respectively. On the other hand, network polysilanes are associated with both direct and indirect band gaps of the order of 2-3 eV which are nearly degenerate and electronic properties can be tailored through surface chemical derivatization ${ }^{6-11}$. These are generally considered as soluble models of amorphous silicon and best

*For correspondence represented as two-dimensional sheet-like structures comprising of linear, branched and cyclic components. Based on controlled vacuum pyrolysis studies of a number of network polysilanes, Fujuki et al. have demonstrated that the materials derived there from exhibit a wide range of visible light (blue to red) emissions at $77 \mathrm{~K}$ as a result of structural transformation which resembles that of siloxene-like, multilayered sheet structure. ${ }^{12}$

An emerging offshoot in this area relates to synthesis of copolymers incorporating linear polysilane units $\left[\mathrm{R}_{2} \mathrm{Si}\right]_{\mathrm{n}}$ in the structural framework. ${ }^{13-16} \mathrm{~A}$ primary impetus for these studies is to utilize the reducing property of polysilanes towards noble metal ions such as $\mathrm{Ag}(\mathrm{I}), \mathrm{Au}(\mathrm{III}), \mathrm{Pd}(\mathrm{II})$ and $\mathrm{Pt}(\mathrm{IV})$, etc. for the synthesis of metal nanoparticles within the polymer scaffolds. Potential applications of such nano assemblies as catalysts for hydrogenation, Suzuki, Sonagashira coupling and hydrosilylation reactions have been reported.

As part of our interest in polysilane chemistry, ${ }^{17-20}$ it has been our endeavour to address synthetic issues related to linear, branched and network polysilanes bearing functionally substituted sila-alkyl side chains. In this respect, classical methods involving Wurtz coupling and catalytic dehydrocoupling reactions as well as chemical modification of preformed polysilanes have been examined and some new perspectives emerging from these studies are reviewed here. The intrinsic variations in HOMO-LUMO band-gap energies associated with different framework structures as well as electronic attributes of side chain substituents have provided an improved insight into the specific roles of these 
polymers for the generation and stabilization of silver nanoparticles. The article summarizes some of our recent results in this area.

\section{Experimental}

\subsection{General comments}

The solvents such as $n$-hexane, diethylether, tetrahydrofuran, ethanol and toluene were dried by standard methods. ${ }^{21}$ The silicon reagents, 2-thienyl lithium, $n$ butyl lithium, lithium aluminium hydride, silver acetate and Karstedt's catalyst (Aldrich) were used as received. Molecular weights of polysilanes (with respect to polystyrene standards) with THF as eluent were estimated using Hitachi ELITE Lachrom chromatograph equipped with L-2490 refractive index detector and waters styragel HR3 and HR4 columns in series. UVvis and photoluminescence spectra (RT, cyclohexane or toluene) of polysilanes as well as AgNPs assemblies derived therefrom were recorded on a Perkin Elmer (Lambda Bio 20) spectrophotometer and Fluorolog-3 modular spectrofluorometer purchased from HorobaJobin Yvon, Inc. respectively. ${ }^{1} \mathrm{H},{ }^{13} \mathrm{C}$ and ${ }^{29} \mathrm{Si}$ NMR spectra were recorded in $\mathrm{CDCl}_{3}$ on Bruker Spectrospin DPX $300 \mathrm{MHz}$ instrument. All synthetic operations were performed using standard Schlenk line techniques under dry nitrogen atmosphere unless otherwise stated.

\subsection{Synthetic methods}

The synthetic procedures for the carbosilane monomers, $\mathrm{RSiCl}_{3} / \mathrm{RR}^{1} \mathrm{SiCl}_{2}\left(\mathrm{R}=\mathrm{Et}_{3} \mathrm{SiCH}_{2} \mathrm{CH}_{2}, 2-\mathrm{Fu} / 2-\right.$ $\mathrm{ThMe}_{2} \mathrm{SiCH}_{2} \mathrm{CH}_{2}, n$-Hex, $\mathrm{R}^{1}=\mathrm{Me}$ ) as well as the corresponding polysilynes/poly(dialkylsilane)s involving Wurtz coupling ( $\mathrm{Na}$ dispersion, $110^{\circ} \mathrm{C}$, toluene) or modified Wurtz coupling approach ( $\mathrm{Na}$ dispersion, RT, THF) are described in references 21, 24 and 25. The details of one representative polymer from among each family, i.e., [2- $\left.\mathrm{ThMe}_{2} \mathrm{Si}\left(\mathrm{CH}_{2}\right)_{3}(\mathrm{Me}) \mathrm{Si}\right]_{\mathrm{n}}$ and [2$\left.\mathrm{ThMe}_{2} \mathrm{Si}\left(\mathrm{CH}_{2}\right)_{3} \mathrm{Si}\right]_{\mathrm{n}}$ under room temperature Wurtz coupling conditions are given here.

In a typical procedure, freshly weighed sodium $(2.0 \mathrm{~g}, 86.8 \mathrm{mmol})$ was heated in refluxing toluene under dry nitrogen atmosphere with vigorous stirring till it is transformed into a fine dispersion. Toluene was removed using a hypodermic syringe while maintaining the temperature of the reaction flask at $110^{\circ} \mathrm{C}$. THF $(100 \mathrm{~mL})$ was added while continuously stirring the dispersion and the contents were gradually brought to room temperature. The carbosilane precursor, 2-

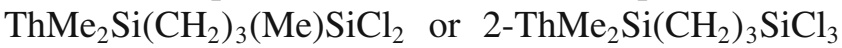
$(38.0 \mathrm{mmol}$ ) was added drop-wise into the sodium dispersion at room temperature and the reaction was allowed to proceed for $20 \mathrm{~h}$. The deep blue coloured solution was filtered under nitrogen and the solvent was stripped off from the filtrate. The crude polymer obtained in each case was subjected to careful fractionation using toluene/2-propanol mixture (1:1). The high molecular weight polymer was obtained as viscous gum while the low molecular weight oligosilanes remain soluble in the solvent mixture. A careful monitoring of high molecular weight fraction was performed by GPC and fractionation is repeated till the oligosilanes are completely removed.

The synthetic procedure for $\left[\mathrm{RMe}_{2} \mathrm{Si}\left(\mathrm{CH}_{2}\right)_{\mathrm{x}} \mathrm{SiH}\right]_{n}$ ( $\mathrm{R}=2$-Th, 4-Me-2-Th, ref. ${ }^{22}$ ) involves the reaction of the carbosilane precursors, $\mathrm{RMe}_{2} \mathrm{Si}\left(\mathrm{CH}_{2}\right)_{\mathrm{x}} \mathrm{SiH}_{3}(20 \mathrm{mmol})$ with $\mathrm{Cp}_{2} \mathrm{TiCl}_{2}(0.13 \mathrm{~g}, 0.52 \mathrm{mmol})$ and $\mathrm{n}-\mathrm{BuLi}$ $\left(0.71 \mathrm{~mL}, 1.6 \mathrm{M}\right.$ in hexane) at $50^{\circ} \mathrm{C}^{22}$ The reaction turns blue in colour suggesting the onset of dehydrocoupling. The content in each case was kept in open till the catalyst becomes deactivated and the intense blue colour disappears. The resulting crude product was dissolved in $n$-hexane and the desired polymer was precipitated by addition of methanol.

\section{Results and discussion}

\subsection{Synthesis of linear, branched and network polysilanes via Wurtz coupling method and their spectroscopic studies}

The scope of classical Wurtz coupling reaction $(\mathrm{Na}$ dispersion, $110^{\circ} \mathrm{C}$, toluene) for polymerization of the carbosilane monomers, $\mathrm{RMeSiCl}_{2} / \mathrm{RSiCl}_{3} \quad(\mathrm{R}=2$ $\mathrm{ThMe}_{2} \mathrm{Si}\left(\mathrm{CH}_{2}\right)_{\mathrm{x}}$ or $\left.2-\mathrm{FuMe}_{2} \mathrm{Si}\left(\mathrm{CH}_{2}\right)_{\mathrm{x}}, \mathrm{x}=2,3\right)$ bearing thienyl (Th) or furyl (Fu) groups has been studied in detail. These carbosilanes have been synthesized by hydrosilylation reaction between an appropriate vinyl/ allylsilane and triorganosilane in the presence of Karstedt's catalyst (scheme 1).
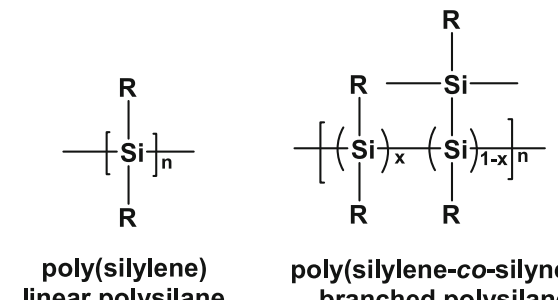

poly(silylene-co-silyne) branched polysilane

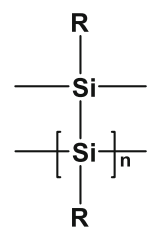

poly(silyne) network polysilane

Chart 1. Classification of polysilanes. 


$$
\begin{aligned}
& \mathrm{RMe}_{2} \mathrm{SiH}+\mathrm{R}^{\prime} \mathrm{SiMeCl}_{2} \stackrel{\text { [cat], } 90^{\circ} \mathrm{C}}{\longrightarrow} \mathrm{RMe}_{2} \mathrm{Si}\left(\mathrm{CH}_{2}\right)_{\mathrm{x}} \mathrm{SiMeCl}_{2}
\end{aligned}
$$

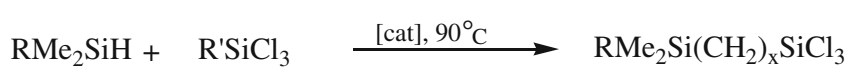

$$
\begin{aligned}
& \mathrm{R}=2-\mathrm{Th}, 2-\mathrm{Fu}, 4-\mathrm{Me}-2-\mathrm{Th}, 5-\mathrm{Me}-2-\mathrm{Fu} \text {; } \\
& \mathrm{R}^{\prime}=\mathrm{CH}_{2}=\mathrm{CH}, \mathrm{CH}_{2}=\mathrm{CHCH}_{2} ; \mathrm{x}=2,3
\end{aligned}
$$

Scheme 1. Synthesis of monomers.

Although Wurtz coupling method is tolerant to furyl groups in the monomers, the carbosilane precursors bearing thienyl groups are found to be intolerant to harsh reaction conditions and invariably resulted in the formation of an intractable yellow solid in each case which could not be characterized further. ${ }^{23}$ Reductive coupling of these monomers has been examined under mild conditions following the modified procedure as reported by Jones and Holder. ${ }^{24,25}$ The method subscribes to room temperature condition and use of polar solvent such as THF for polymerization of dichlorodiorganosilanes with sodium metal. This approach has allowed the isolation of desired polysilanes with thienylsubstituted sila-alkyl side chains. In general, the method is found to be advantageous since dehalocondensation

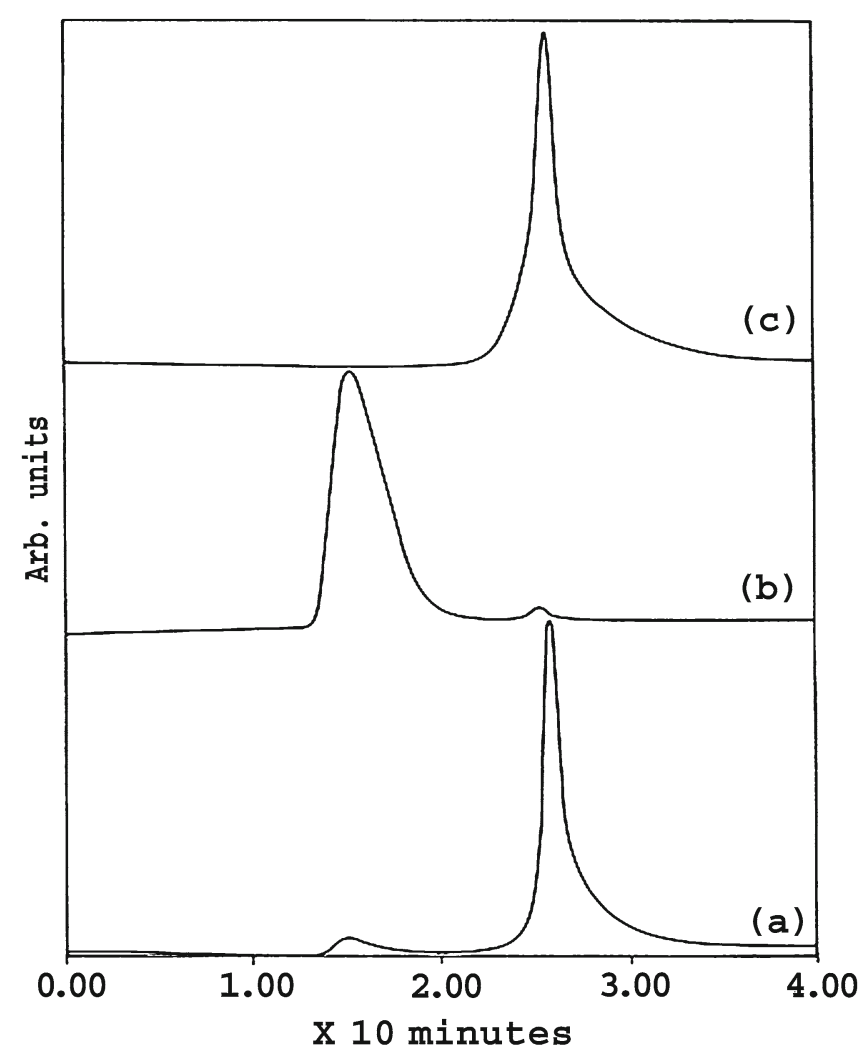

Figure 1. GPC profiles of (a) crude mixture (b) high molecular weight polysilane and (c) cyclic/low molecular weight oligomers of $\left[\mathrm{ThMe}_{2} \mathrm{Si}\left(\mathrm{CH}_{2}\right)_{2} \mathrm{SiMe}\right]_{n}$. of di/trichlorosilanes under these conditions results in the isolation of polysilanes with substantial increase in molecular weight as well as relative percentage of high molecular weight fraction as compared to those obtained from classical Wurtz coupling method. A number of branched polysilanes, $\left[(\mathrm{PhMeSi})_{\mathrm{x}}-\mathrm{co}-(\mathrm{RSi})_{1-\mathrm{x}}\right]_{\mathrm{n}}(\mathrm{R}=$ $\mathrm{Et}_{3} \mathrm{SiCH}_{2} \mathrm{CH}_{2}, 2-\mathrm{FuMe}_{2} \mathrm{SiCH}_{2} \mathrm{CH}_{2}$, n-Hex, Ph; $\mathrm{x}=$ $0.8-0.5)$ have also been synthesized by reductive Wurtz coupling of a mixture of di-/trichlorosilane in different feed ratios. ${ }^{26}$ The separation of high molecular weight polysilanes from the crude mixture by solvent extraction approach (see section 2) is an essential step which effectively removes the cyclics and low molecular weight oligomers, as shown in figure 1 . The results obtained from gel permeation chromatography (GPC) of a few selected polymers are summarized in table 1 .

The identity of each polymer is established by IR and multinuclear $\left[{ }^{1} \mathrm{H},{ }^{13} \mathrm{C}\left\{{ }^{1} \mathrm{H}\right\}\right.$ and $\left.{ }^{29} \mathrm{Si}\left\{{ }^{1} \mathrm{H}\right\}\right]$ NMR spectroscopy. The UV-vis spectral studies of linear polysilanes reveal an absorption band at 305-315 nm associated with $\sigma-\sigma^{*}$ electronic transitions. As shown in table 1 , a red shift in the absorption maxima as well as increase in molar absorptivity values is discernable in polysilanes with increasing chain length $(x=3)$ of the appended sila-alkyl substituents, suggesting a more extended trans conformation of the silicon backbone in solution. For branched polysilanes, UV-vis and PL spectra respond to two distinct chromophores associated with linear and branched segments and are in conformity with the results reported earlier. ${ }^{4,5}$ Cyclic voltammetric studies of this class of polysilanes (reference electrode: $\mathrm{Hg} / \mathrm{Hg}_{2} \mathrm{Cl}_{2}$ ) reveal two distinct onsets of oxidation $\left(\mathrm{V}_{i}\right)$ at $0.84-0.89$ and $0.36 \mathrm{~V}$ corresponding to linear poly(methylphenylsilane) and polysilyne units respectively. ${ }^{26}$

\subsection{Synthesis and characterization of poly(hydrosilane)s}

During a systematic study on Ti-catalysed dehydrocoupling of various primary organosilanes, ${ }^{17,18}$ it is observed that 2-thienylsilane or 2-furylsilane in presence of $\mathrm{Cp}_{2} \mathrm{TiCl}_{2} / \mathrm{n}$-BuLi as catalyst does not undergo catenation while similar reactions proceed smoothly 
Table 1. GPC and UV-vis spectral data for selected linear, branched and network polysilanes.

\begin{tabular}{|c|c|c|c|}
\hline Sl. No & Polymer & $\mathrm{M}_{\mathrm{w}} \times 10^{4} / \mathrm{PDI}(\mathrm{x}=2,3)$ & UV-vis/PL $\left(\lambda_{\max } n m\right)$ \\
\hline 1 & {$\left[(2-\mathrm{Fu}) \mathrm{Me}_{2} \mathrm{Si}\left(\mathrm{CH}_{2}\right)_{\mathrm{x}} \mathrm{SiMe}\right]_{\mathrm{n}}$} & $3.4 / 1.22(5.4 / 1.28)$ & $305(313) / 340(350)$ \\
\hline 2 & {$\left[(5-\mathrm{Me}-2-\mathrm{Fu}) \mathrm{Me}_{2} \mathrm{Si}\left(\mathrm{CH}_{2}\right)_{\mathrm{x}} \mathrm{SiMe}\right]_{\mathrm{n}}$} & $4.2 / 1.47(3.3 / 1.39)$ & $303(312) / 337(346)$ \\
\hline 3 & {$\left[(2-\mathrm{Th}) \mathrm{Me}_{2} \mathrm{Si}\left(\mathrm{CH}_{2}\right)_{\mathrm{x}} \mathrm{SiMe}\right]_{\mathrm{n}}$} & $10.2 / 1.58(10.4 / 1.51)$ & $300(309) / 335(346)$ \\
\hline 4 & {$\left[(4-\mathrm{Me}-2-\mathrm{Th}) \mathrm{Me}_{2} \mathrm{Si}\left(\mathrm{CH}_{2}\right)_{\mathrm{x}} \mathrm{SiMe}\right]_{\mathrm{n}}$} & 9.1/1.45(14.4/1.61) & $302(315) / 334(346)$ \\
\hline 5 & {$\left[(\mathrm{PhMeSi})_{0.8}-c o-\left(2-\mathrm{FuMe}_{2} \mathrm{SiCH}_{2} \mathrm{CH}_{2} \mathrm{Si}\right)_{0.2}\right]_{\mathrm{n}}$} & $0.98 / 1.91$ & 330,390 (tailing band)/363, $430(\mathrm{br})$ \\
\hline 6 & {$\left[2-\mathrm{FuMe}_{2} \mathrm{SiCH}_{2} \mathrm{CH}_{2} \mathrm{Si}\right]_{\mathrm{n}}$} & $0.91 / 1.54$ & 410 (tailing band)/435 (br) \\
\hline
\end{tabular}

Polymers in Sl. No. 3, 4 and 6 have been synthesized by modified Wurtz coupling approach (THF, RT). The values in parentheses are for polymers with $\mathrm{x}=3$.

with the precursor carbosilanes, $\mathrm{RMe}_{2} \mathrm{Si}\left(\mathrm{CH}_{2}\right)_{\mathrm{x}} \mathrm{SiH}_{3}$ $(\mathrm{R}=2-\mathrm{Th}, 4-\mathrm{Me}-2-\mathrm{Th}, \quad 2-\mathrm{Fu}, 5-\mathrm{Me}-2-\mathrm{Fu} ; \mathrm{x}=$ $2,3)$ to afford the corresponding oligosilanes, $\left[\mathrm{RMe}_{2} \mathrm{Si}\left(\mathrm{CH}_{2}\right)_{\mathrm{x}} \mathrm{SiH}\right]_{\mathrm{n}}$ with average molecular weight $\left(\mathrm{M}_{\mathrm{w}}\right)$ ranging between 1.6-2.6 $\times 10^{3}$ (scheme 2). ${ }^{22}$ A plausible mechanism based on previously known $\sigma$-bond metathesis pathway ${ }^{27}$ has been proposed to explain preferential affinity of the carbosilanes towards dehydrogenative coupling. It has been suggested that passive nature of 2-thieny/2-furylsilane towards dehydrocoupling results from intramolecular coordinative association of the sulphur atom with [Ti] centre associated with intermediate metal-silyl complex, $\mathrm{Cp}_{2} \mathrm{M}(\mathrm{H})\left(\mathrm{SiH}_{2} \mathrm{R}\right)(\mathrm{M}=\mathrm{Ti}, \mathrm{R}=2$ - $\mathrm{Th})$ which prevents step growth polymerization process in these monomers. In case of carbosilanes, donor interaction between the active metal centre and thienyl group is avoided by the inclusion of bridging methylene groups and thus favours chain growth during polymerization.

\subsection{Chemical modification of poly(hydrosilane)s}

An alternative approach to functional polysilanes bearing thienyl substituted sila-alkyl side chains is chemical modification of preformed poly(hydrosilane).$^{28}$ The method involves free radical hydrosilylation of $\mathrm{Si}-\mathrm{H}$ bonds with an appropriate allyl/vinyl silane. Using this

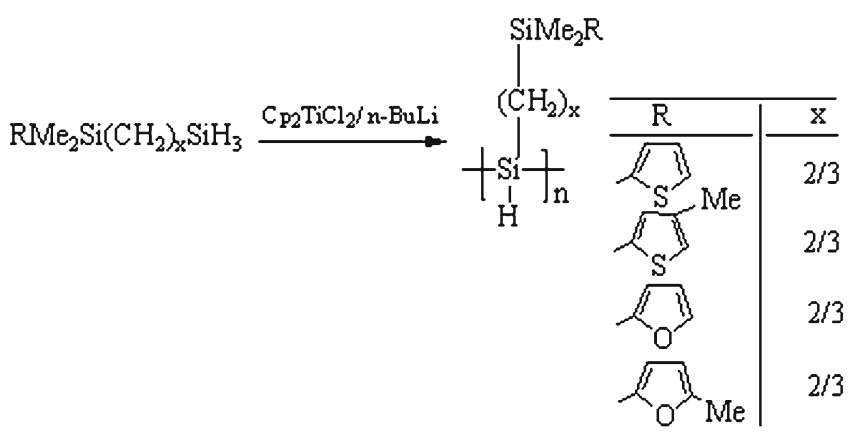

Scheme 2. Synthesis of poly(hydrosilane)s. approach, a number of linear polysilanes have been synthesized as shown in scheme 3. The residual $\mathrm{SiH}$ content in the resulting polymers was found to be less than $20 \%$ thereby suggesting that the method is quite effective for the introduction of thienyl groups on the polymer side chains.

\subsection{Reducing behaviour of polysilanes towards Ag(I) ions - A mild synthetic approach for stable silver nanoparticles in organosilicon polymer matrices}

The polysilanes described above are associated with linear, branched or network structural frameworks and possess donor substituents on the side chains. These characteristic structural features as well as distinct oxidation potential of each family of polymers have provided an impetus to address their potential applications in the generation and stabilization of noble metal nanoparticles. Such studies are found to be relevant in view of adequate information in literature pertaining to the role of neutral donor ligands (thiols, amines, phosphines, etc.) on a dendritic/polymer support in controlling the growth and stabilization of noble metal nanoparticles. ${ }^{29-32}$

A general synthetic protocol for the synthesis of silver nanoparticles (AgNPs) involves the addition of an appropriate polysilane into a suspension of silver tetrafluoroborate/silver acetate in toluene/cyclohexane under aerobic conditions with varying feed ratios of $\mathrm{Ag}^{+}$ions. In each case, a slow dissolution of the metal salt is accompanied by a distinct appearance of pale yellow colour in the resulting solution, suggesting the formation of AgNPs. An examination of UV-vis spectral profiles at different time intervals reveal that the Plasmon resonance band at $420-435 \mathrm{~nm}$ is intensified with time and finally becomes constant after $3-4 \mathrm{~h}$. The resulting solutions have been subjected to TEM studies which reveal spherical monodispersed AgNPs with an average size of 4-8 nm. 


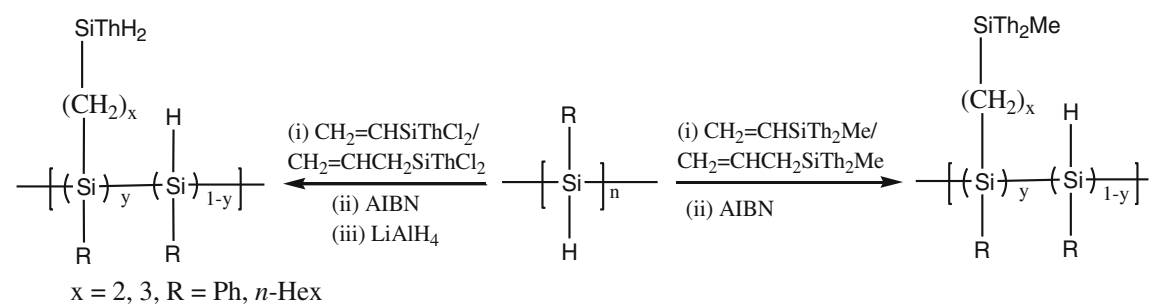

Scheme 3. Chemical modification of poly(hydrosilane)s.

A comparative study of linear, branched and network polysilanes has brought to light some significant variations in the optical properties of the resulting polymersilver nanocomposites and are summarized as follows.

(a) In case of branched ${ }^{26}$ and network polysilanes ${ }^{33}$ (S1. No. 5, 6; table 1), the resulting silver nanoassemblies are fluorescent in the green light region, as evident from the appearance of a new emission band at $\sim 530 \mathrm{~nm}$ in the photoluminescence (PL) spectra. This optical phenomenon is attributed to the formation of $\mathrm{Ag}$ nanoclusters in conjunction with nanoparticles, as no fluorescence emission is expected from bulk AgNPs. ${ }^{34,35}$ Time resolved fluorescence studies of the silver nanocomposites have shown fluorescence life time of the order of $2.84 \mathrm{~ns}$ which corroborate well with those reported earlier for $\mathrm{Ag}$ nanoclusters. ${ }^{35-37} \mathrm{It}$ has been concluded that stronger reducing ability [oxidation potential $\left(\mathrm{V}_{i}\right): 0.34-0.36,0.84 \mathrm{~V}$ (for branched polysilanes); $0.35 \mathrm{~V}$ (for network polysilanes)] as well as higher dimensional framework structures are the key factors which assist the formation and stabilization of Ag nanoclusters in these composites. To get a better insight into these factors, the reaction of a mixture of homopolymers $[\mathrm{PhMeSi}]_{\mathrm{n}}$ and $\left[\mathrm{Et}_{3} \mathrm{SiCH}_{2} \mathrm{CH}_{2} \mathrm{Si}\right]_{\mathrm{n}}$ (5:1 equivalents) with 0.10 equivalent of silver acetate in toluene has been performed under identical conditions. The formation of AgNPs of average diameter, $12.75 \pm 4.02$ is evident from TEM image while UV-vis spectrum exhibits a distinct surface plasmon resonance at $425 \mathrm{~nm}$. Nevertheless, the nanocomposite thus formed does not exhibit fluorescent characteristics and is devoid of emission band at $\sim 525 \mathrm{~nm}$ in a range of excitation wavelengths between 350 and $430 \mathrm{~nm}$. These studies clearly suggest that the matrix derived from physical blend of the homopolymers does not meet the structural requirements which are essential for the stabilization of Ag nanoclusters.

(b) For linear polysilanes of composition, [\{2$\left.\left.\mathrm{ThH}_{2} \mathrm{Si}\left(\mathrm{CH}_{2}\right)_{2} \mathrm{Si}(\mathrm{R})\right\}_{\mathrm{x}}\{\mathrm{HSi}(\mathrm{R})\}_{1-\mathrm{x}}\right]_{\mathrm{n}},(\mathrm{R}=\mathrm{Ph}, n-$ Hex), inclusion of thienyl/furyl groups on the appended sila-alkyl side chains is essential to stabilize the in situ generated AgNPs which exhibit long shelf life stability ( $>3$ months) in cyclohexane without any perceptible change in their size domain. ${ }^{28}$

(c) An important property of poly(alkylarylsilane)s, $\left[\mathrm{Et}_{3} \mathrm{Si}\left(\mathrm{CH}_{2}\right)_{2} \mathrm{Si}\left(\mathrm{C}_{6} \mathrm{H}_{4} \mathrm{R}\right)\right]_{\mathrm{n}}[\mathrm{R}=\mathrm{H}, p-\mathrm{Me}, p-\mathrm{OMe}$, $\left.p-\mathrm{NMe}_{2}\right]$ is their variable oxidation potential $\left[\left(\mathrm{V}_{\text {peak }}\right): 0.95\right.$ to $\left.0.49 \mathrm{~V}\right] .{ }^{38}$ These features are consistent with the results obtained from UVvis spectra which exhibit a progressive red shift ( $\sigma-\sigma^{*}$ transition: $\lambda_{\max }: 320-342 \mathrm{~nm}$, table 2 ) in polysilanes bearing functionalities with increasing electron donating strength on the phenyl ring. A systematic study has been performed to understand the reducing behaviour of these polymers with a large window of available oxidation potentials towards $\operatorname{Ag}(\mathrm{I})$ salts. This approach is found to be quite unique for 'size selective' synthesis of AgNPs with optimized size domains ranging between 21.0 and $4.8 \mathrm{~nm}$ which can be correlated with the relative reducing strength of different polysilanes (table 2). It is evident that smaller size nanoparticles are formed by the use of polysilanes with lower oxidation potential (higher $\lambda_{\max }$ ).

\subsection{Compositional aspects of host polymer matrices and their relevance in the stabilization of silver nanoclusters}

The host polymer matrices are isolated from silver nanocomposites by addition of a donor solvent such as

Table 2. Cyclic voltammetric/UV-vis spectral data of linear poly(alkylarylsilane)s and particle size of AgNPs from TEM studies.

\begin{tabular}{lcc}
\hline Polysilane & $\begin{array}{c}\mathrm{V}_{\text {peak }}(\mathrm{V}) / \\
\lambda_{\text {max }}(\mathrm{nm})\end{array}$ & $\begin{array}{c}\text { Particle } \\
\text { size }(\mathrm{nm})\end{array}$ \\
\hline$\left[\mathrm{Et}_{3} \mathrm{Si}\left(\mathrm{CH}_{2}\right)_{2} \mathrm{Si}\left(\mathrm{C}_{6} \mathrm{H}_{5}\right)\right]_{\mathrm{n}}$ & $0.95 / 320$ & $21.0 \pm 3.2$ \\
{$\left[\mathrm{Et}_{3} \mathrm{Si}\left(\mathrm{CH}_{2}\right)_{2} \mathrm{Si}\left(p-\mathrm{MeC}_{6} \mathrm{H}_{4}\right)\right]_{\mathrm{n}}$} & $0.88 / 323$ & $17.4 \pm 2.9$ \\
{$\left[\mathrm{Et}_{3} \mathrm{Si}\left(\mathrm{CH}_{2}\right)_{2} \mathrm{Si}\left(p-\mathrm{OMeC}_{6} \mathrm{H}_{4}\right)\right]_{\mathrm{n}}$} & $0.79 / 332$ & $10.1 \pm 2.5$ \\
{$\left[\mathrm{Et}_{3} \mathrm{Si}\left(\mathrm{CH}_{2}\right)_{2} \mathrm{Si}\left(p-\mathrm{NMe}_{2} \mathrm{C}_{6} \mathrm{H}_{4}\right)\right]_{\mathrm{n}}$} & $0.49 / 342$ & $4.8 \pm 0.6$ \\
\hline
\end{tabular}


THF and examined by GPC, IR and ${ }^{29} \mathrm{Si}$ NMR spectroscopy. ${ }^{28,38}$ It has been observed that reducing action of the parent polysilanes towards $\mathrm{Ag}(\mathrm{I})$ ions results in substantial decrease in the molecular weights and inclusion of siloxane groups in the host polymer matrices (IR: $1070-1080 \mathrm{~cm}^{-1}$ ). In case of branched polysilanes, ${ }^{26} \mathrm{UV}$-vis and PL spectra of host polymers identify linear polysilane segment by characteristic absorption and emission bands at 330 and 360-365 nm, respectively, while spectral signatures due to polysilyne units are absent. Based on these results, it has been concluded that the branched polysilyne units in the parent polymers act as preferential sites for the reduction of $\operatorname{Ag}(\mathrm{I})$ ions to $\operatorname{Ag}(0)$.

\section{Conclusions}

Synthetic aspects for linear, branched and network polysilanes bearing thienyl/furyl substituted sila-alkyl side chains are presented. A detailed study on the reactivity behaviour of each class of polymers with silver acetate/silver tetrafluoroborate in toluene or cyclohexane has provided a mild approach for the isolation of stable AgNPs/nanoclusters into the scaffolds of the polymer matrices. In this respect, the results obtained from branched and network polysilanes are particularly noteworthy in view of the fluorescence characteristics of the nanocomposites derived therefrom. The stability of in situ generated AgNPs is greatly enhanced with the inclusion of 2-thienyl substituted sila-alkyl side chains in linear polysilanes. In case of poly(alkylarylsilane)s, $\left[\mathrm{Et}_{3} \mathrm{Si}\left(\mathrm{CH}_{2}\right)_{2} \mathrm{Si}\left(\mathrm{C}_{6} \mathrm{H}_{4} \mathrm{R}\right)\right]_{\mathrm{n}}[\mathrm{R}=\mathrm{H}, p$-Me, $p$-OMe, $p$ $\mathrm{NMe}_{2}$ ], the intrinsic variations of oxidation potentials have been successfully utilized for the 'size controlled' synthesis of AgNPs.

\section{Acknowledgements}

Financial grant from the Department of Science and Technology (DST), New Delhi, India (Project No. SR/ S1/IC-25/2007) is gratefully acknowledged. The authors (US and VS) thank the Council of Scientific and Industrial Research (CSIR), India for providing JRF/SRF.

\section{References}

1. Michl J and West R 2000 In: Silicon-containing polymers: The science and technology of their synthesis and applications, R G Jones, W Ando, J Chojnowski (eds), Dodrecht, The Netherlands; Kluwer, p 499

2. Miller R D and Michl J 1989 Chem. Rev. 891359

3. Watanab A 2003 J. Organomet. Chem. 685122

4. Watanabe A, Miike H, Tsutsumi Y and Matsuda M 1993 Macromolecules 262111
5. Walree C A, Cleij T J, Jenneskens L W and Vlietstra E J 1996 Macromolecules 297362

6. Bianconi P A and Weidman T W 1988 J. Am. Chem. Soc. 1102342

7. Furukawa K, Fujino M and Matsumoto N 1990 Macromolecules 233423

8. Bianconi P A, Schilling F C and Weidman T W 1989 Macromolecules 221697

9. Vink R L C, Barkema G T, Walree C A V and Jenneskens L W 2002 J. Chem. Phys. 116854

10. Fukao S and Fujiki M 2009 Macromolecules 408062

11. Cleij T J, Stellar T K Y and Jenneskens L W 1999 Macromolecules 323286

12. Fujiki M, Kawamoto Y, Kato M, Fujimoto Y, Saito T, Hososhima S and Kwak G 2009 Chem. Mater. 212459

13. Sakurai H 2006 Proc. Jpn. Acad. Ser. B 82257

14. Oyamada H, Naito T, Miyamoto S, Akiyama R, Hagio H and Kobayashi S 2008 Org. Biomol. Chem. 661

15. Fukushima M, Noguchi N, Aramata M, Hamada Y, Tabei E, Mori S and Yamamoto Y 1998 Synth. Met. 97 273

16. Oyamada H, Akiyama R, Hagio $H$, Naito $T$ and Kobayashi S 2006 Chem. Commun. 4297

17. Shankar R, Saxena A and Brar S A 2001 J. Organomet. Chem. $\mathbf{6 2 8} 262$

18. Shankar R, Saxena A and Brar S A 2002 J. Organomet. Chem. 650223

19. Shankar R and Joshi A 2006 J. Organomet. Chem. 691 3310

20. Shankar R and Joshi A 2005 Macromolecules 384176

21. Armarego W L F and Perrin D D 1996 Purification of laboratory chemicals $\left(4^{\text {th }}\right.$ ed) Elsevier Oxford

22. Shankar R and Shahi V 2009 J. Organomet. Chem. 694 1339

23. Shankar R and Shahi V 2008 J. Polym. Sci. Part A: Polym. Chem. $\mathbf{4 6} 7816$

24. Holder S J, Achilleos M and Jones R G 2005 Macromolecules $\mathbf{3 8} 1633$

25. Jones R G and Holder S 2006 J. Polym. Int. 55711

26. Shankar R, Sahoo U and Shahi V 2011 Macromolecules 443240

27. Corey J Y, Zhu X-H, Bedard T C and Lange L D 1991 Organometallics $\mathbf{1 0} 924$

28. Shankar R and Shahi V 2008 J. Organomet. Chem. 693 307

29. Li Y and El-Sayed M A 2001 J. Phys. Chem. B 1058938

30. Shon Y-S and Choi D 2007 Curr. Nanosci. 3245

31. Hoogesteen W and Fokkink L G J 1995 J. Colloid. Interface. Sci. $\mathbf{1 7 5} 12$

32. Wu L, Li Z W, Zhang F, He Y M. and Fan Q H 2008. Adv. Synth. Catal. 350846

33. Shankar R and Sahoo U 2012. J. Polym. Sci. Part A: Polym. Chem. $\mathbf{5 0} 1158$

34. Adhikari B and Banerjee A 2010 Chem. Mater. 224364

35. Maretti L, Billone P S, Liu Y and Scaiano J C 2009 J. Am. Chem. Soc. 13113972

36. Vosch T, Antoku Y, Hsiang J C, Richards C I, Gonzalez J I and Dickson R M 2007 Proc. Natl. Acad. Sci. USA 10412616

37. Fedrigo S, Harbich W and Buttet J 1991 J. Chem. Phys. 99a 5712

38. Shankar R, Shahi V and Sahoo U 2010 Chem. Mater. 22 1367 